\title{
The relationship between tension reduction and ethanol consumption in rats
}

\author{
JOSEPH R. VOLPICELLI, JOANNE TIVEN, and STEVEN C. KIMMEL \\ University of Pennsylvania, Philadelphia, Pennsylvania
}

\begin{abstract}
It is generally assumed that organisms drink ethanol during stress in order to reduce anxiety. We tested this prediction by investigating the effects of inescapable shock in relation to living conditions and the temporal pattern of ethanol consumption. Adult male rats received 60 trials of 2-sec-duration 1.0-mA inescapable shock each day throughout shock training. Contrary to the tension-reduction prediction, when subjects were given a choice between water and $5 \%$ ethanol, the rats living in the fearful shock environment consumed less ethanol than the rats that returned to their home cages (safety cages) after shock treatment. In addition, rats showed an increase in ethanol consumption, but only on the days following experience with inescapable shock. These results are inconsistent with the tension-reduction hypothesis and suggest that rats drink ethanol, not during, but when recovering from tension-arousing events.
\end{abstract}

For the past quarter century, animal researchers have empirically investigated the question, "Why do organisms drink alcohol?" It has been commonly assumed that organisms drink alcohol because it reduces tension. Conger (1956) assumed that alcohol reduces tension pharmacologically and that organisms are reinforced for drinking it by tension-reducing effects. The empirical support for this "tensionreduction hypothesis"' (TRH) is conflicting and paradoxical (Cappell \& Herman, 1972). If ethanol is reinforcing because it reduces tension, then ethanol drinking should increase during stressful situations. Myers and Holman (1967), however, report that the stress of electric shock fails to increase ethanol drinking in rats. In contrast, other researchers report that ethanol consumption does indeed increase in stressful situations (e.g., Anisman \& Waller, 1974; Cicero, Myers, \& Black, 1968; Clark \& Polish, 1960; Derr \& Lindblad, 1980; Masserman \& Yum, 1946; Mills, Bean, \& Hutcheson, 1967).

Part of this confusion results from procedural differences and a failure to account for the temporal pattern of ethanol consumption. For example, Casey (1960) found that ethanol consumption increased only modestly during inescapable shock stress, but increased dramatically after shock experience ended, with peak ethanol drinking occurring 16 days after the last shock.

This research was supported by NIH Medical Scientist Training Grant GM 07170 to J. R. Volpicelli and by NIMH Grant 19604 to M. E. P. Seligman. The authors wish to thank M. E. P. Seligman for his helpful comments on an earlier draft of this manuscript. Requests for reprints should be sent to J. R. Volpicelli, Department of Psychology, University of Pennsylvania, Philadelphia, Pennsylvania 19104.

-Article accepted by previous editor, Richard F. Thompson.
Casey's results suggest that a necessary condition to observe an increase in alcohol self-selection is that animals have a postshock safety period. This helps us resolve an apparent contradiction between two similar experiments. Anisman and Waller (1974) found that daily periods of electric footshock (2-sec duration, 1.0-mA intensity) given every $3 \mathrm{~min}$, alternated with 6- or 12 -h periods of no shock, significantly increased alcohol consumption (from $2 \%$ to $10 \%$ ethanol solution). In contrast, Myers and Holman (1967) failed to find an increase in alcohol consumption (from $3 \%$ to $20 \%$ ethanol solution) when uncontrollable footshock of 2.5-sec duration and .7-mA intensity was administered one or six times per hour over a 14-day period. The key difference between the two designs is the presence or absence of a shock-free period. If safety is necessary to increase ethanol consumption, then without nonshock relief periods, as in the Myers and Holman experiment, we would expect to see no increase in ethanol drinking.

We tested the TRH by comparing ethanol consumption in an environment associated with inescapable shocks with that in the shock-free home cage. If rats drink alcohol to reduce tension, they should drink more alcohol when living in an environment associated with inescapable shocks than rats that are returned to the safety cage following shock experience. However, if ethanol consumption increases during the recovery from a fearful situation, then the group returned to their home cages should drink the most ethanol.

\section{METHOD}

Subjects

Subjects were 12 male Sprague-Dawley rats obtained from the Holtzman Company, Madison, Wisconsin. Due to space limitations, the animals were run in two squads of six rats. The animals 
were 90-100 days old (Squad 1) or 115-125 days old (Squad 2) at the start of the experiment and were housed individually under constant light, with food and water and/or 5\% ethanol solution freely available. Rats were nonsystematically assigned to one of two living conditions: safety cage or shock box ( $n=6$ per group).

\section{Apparatus}

The two living conditions consisted of standard Wahman rat cages (No. LC75/A) that served as shock-free environments and three identical shock boxes. The internal diameters of the shock boxes measured $30 \mathrm{~cm}$ wide $\times 30 \mathrm{~cm}$ long $\times 38 \mathrm{~cm}$ high. The side walls were constructed of stainless steel, and the front and rear panels consisted of clear Plexiglas. A food tray hung outside a round $8-\mathrm{cm}$-diam hole in the front panel, $14 \mathrm{~cm}$ above the floor, from which subjects could obtain ad lib Purina Rat Chow by nibbling around the wire mesh that covered the hole. Water and ethanol bottles were hung on the outside of the left stainless steel side wall such that spouts protruded $2 \mathrm{~cm}$ into the shock boxes, $5 \mathrm{~cm}$ from the floor. The floor of the shock boxes consisted of stainless steel grid bars, which were $.4 \mathrm{~cm}$ in diameter and $1.4 \mathrm{~cm}$ apart. A 1.0-mA electric shock was delivered through the grid floor and side walls by a constant-current shock source consisting of a $600-\mathrm{V}$ ac transformer and limiting resistor. Shock was scrambled by a Hoffman and Fleshler (1962) relay circuit scrambler. Food was made available to subjects in the safety cages by a standard Wahman food tray (LC-272 a/Mesh) that hung on the back of the cage. Fluid was available from bottles that hung on the front of the cage, $5 \mathrm{~cm}$ from the floor, such that drinking spouts protruded $4 \mathrm{~cm}$ into the cage.

\section{Procedure}

The experiment consisted of three phases each of 7-day duration. During each of the first 5 days of the three phases, subjects received 60 inescapable shocks of 2-sec duration, delivered on a fixed-time $60-\mathrm{sec}$ (FT-60 sec) schedule. On the last 2 days of each phase, rats were not shocked and remained in their assigned living conditions. In the first phase, water was the only fluid available to the subjects. Throughout the second phase, a $5 \%$ ethanol (V/V) solution was the sole fluid. During the third phase, both water and the $5 \%$ ethanol solution were available to the rats. The amount of water and ethanol consumed and the body weights of the rats were recorded daily. The position of the fluid bottles was alternated daily. Subjects assigned to the safety-cage condition were placed in the shock boxes for $1 \mathrm{~h}$ on shock days, and during this time the rats assigned to the shock-box condition were placed in the safety cages. The order of shock presentations to the safetycage and shock-box groups varied randomly, and the time between successive shock presentations varied between 20 and $28 \mathrm{~h}$ to minimize temporal conditioning cues.

\section{RESULTS}

\section{Phases 1 and 2}

The subjects in the safety-cage and shock-box living conditions did not differ reliably when only water or ethanol was available. As Table 1 shows, rats drank less water during shock days in Phase 1 relative to postshock days. A group $\times$ shock condition analysis of variance reveals a reliable depression of water consumption during shock training $[F(1,10)=14.09$, $\mathrm{p}<.01]$ but no reliable group differences or interactions $(\mathrm{Fs}<1.0)$. Thus, early shock experience depresses water consumption regardless of living conditions. Ethanol consumption was not reliably different $(p<.05)$ across the shock and postshock days. A group $\times$ shock condition analysis of variance reveals no reliable groups, shock condition, or interaction effects $(F s<1.10)$. The only reliable difference
Table 1

Mean Fluid Consumption (in Cubic Centimeters) for Safety Cage (SC) and Shock Box (SB) Living Conditions for Phases 1 and 2

\begin{tabular}{ccccc}
\hline & \multicolumn{2}{c}{ Shock } & & \multicolumn{2}{c}{ Postshock } \\
\cline { 2 - 3 } \cline { 5 - 5 } & Mean & SEM & Mean & SEM \\
\hline \multicolumn{5}{c}{ Phase 1 (Water) } \\
SB & 40.04 & 1.56 & 45.88 & 1.73 \\
SC & 40.21 & 2.13 & 48.67 & 2.63 \\
\multicolumn{4}{c}{ Phase 2 (5\% Ethanol) } \\
SB & 41.37 & 2.58 & 41.08 & 3.23 \\
SC & 42.55 & 2.22 & 43.83 & 3.27 \\
\hline
\end{tabular}

was that rats in the second squad, regardless of living condition, tended to drink more alcohol than rats in the first squad $(46.09$ vs. $38.30 \mathrm{cc})[\mathrm{F}(1,10)=4.62$, $\mathrm{p}<.06]$. The results of the first two phases show that the rats living in the safety cages and shock boxes received about equal experience with water and alcohol.

\section{Phase 3}

In contrast with the first two one-bottle phases, in which subjects chose between water and alcohol in Phase 3, safety dramatically influences alcohol consumption. During the shock days, the rats living in the safety cages showed a greater preference for ethanol than did rats living in the shock boxes. As Figure 1 reveals, the safety-cage group drank more ethanol and less water than the shock-box group. The differences were consistent over both squads, although rats in the second squad generally preferred ethanol relative to the first squad. A group $x$ fluid choice $x$ squad analysis of variance reveals a reliable fluid choice $\times$ group interaction $[F(1,8)=8.04, p<.025]$ and fluid choice $\times$ squad interaction $[F(1,8)=11.33$, $\mathrm{p}<.01$ ]. Post hoc comparisons of the source of this interaction showed that safety-cage rats drank reliably more ethanol and reliably less water than the shock-box subjects. Rats in the safety cages tended to drink more total fluid than the shock-box subjects $[\mathrm{F}(1,8)=3.56, .5<\mathrm{p}<.10]$. Total fluid consumption did not differ across squads, and, in general, rats drank about the same amount of water and ethanol (Fs $<1.0)$.

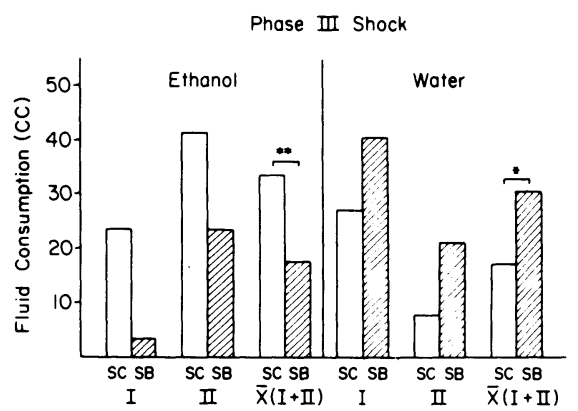

Figure 1. Effects of living in a shock-free safety cage (SC) or shock box (SB) during the 5 days of shock experience of Phase 3 on ethanol and water consumption. [ $I=$ first squad, II = second squad, and $\bar{X}$ (I and II) = mean of first and second squads.] 


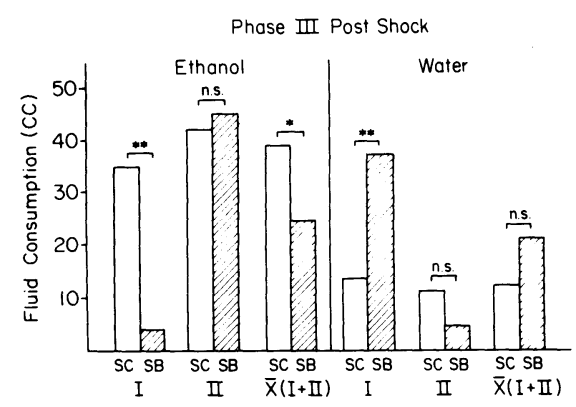

Figure 2. Effects of living in a shock-free safety cage (SC) or shock box (SB) during the 2 postshock days of Phase 3 on ethanol and water consumption. [ $I=$ first squad, $I I=$ second squad, and $\bar{X}(I$ and II $)=$ mean of first and second squads.]

During the 2 postshock days, ethanol preference generally increased for both living conditions. Figure 2 shows that, in the second squad, the subjects living in the shock boxes increased ethanol preference to the same high level as their safety-cage counterparts. However, in the first squad, the rats living in the shock boxes continued to show a strong ethanol aversion and sampled very little ethanol in the postshock period. A group $\times$ fluid choice $\times$ squad analysis reveals that the subjects, regardless of living conditions, preferred ethanol to water $[F(1,8)=7.61$, $\mathrm{p}<.05$ ], rats in the second squad showed greater alcohol preference than rats in the first squad $[F(1,8)$ $=14.30, \mathrm{p}<.01]$, and fluid preference interacted with living conditions and squads $[F(1,8)=9.66$, $\mathrm{p}<.025]$. Post hoc comparisons revealed that the source of this triple interaction is a higher ethanol preference in the safety-cage group of the first squad relative to their counterparts living in the shock boxes.

Within-group comparisons are presented in Table 2, which compares ethanol and water consumption for the last 2 days of shock experience with the 2 postshock days.

These results show clearly that during the 2 postshock days, all rats increased ethanol consumption $[t(11)=3.55, p<.01]$, while water consumption decreased $[\mathrm{t}(11)=2.28, \mathrm{p}<.05]$.

Table 2

Within-Group Comparisons of Mean Fluid Consumption (in Cubic Centimeters) During the Last 2 Days of Shock Experience of Phase 3 and the 2 Days Postshock

\begin{tabular}{|c|c|c|c|}
\hline & Shock & Postshock & Paired $\mathrm{t}$ \\
\hline \multicolumn{4}{|c|}{ SB } \\
\hline Water & 25.42 & 20.75 & $1.50 \dagger$ \\
\hline $5 \%$ Ethanol & 16.40 & 24.50 & $-2.71^{*}$ \\
\hline \multicolumn{4}{|c|}{ SC } \\
\hline Water & 15.58 & 12.00 & $1.04 \dagger$ \\
\hline $5 \%$ Ethanol & 32.41 & 38.33 & $-2.12 \dagger$ \\
\hline \multicolumn{4}{|c|}{ Combined $(\mathrm{SB}+\mathrm{SC})$} \\
\hline Water & 20.61 & 16.38 & $2.28^{*}$ \\
\hline $5 \%$ Ethanol & 24.41 & 31.42 & $-3.55 * *$ \\
\hline
\end{tabular}

Note-SC = safety cage and $S B=$ shock box living conditions. ${ }^{*} p<.05 . \quad{ }^{* *} p<.01$. †Nonsignificant.

\section{DISCUSSION}

The results of this experiment contradict the predictions of the TRH. During shock days ethanol preference was higher in the group that was removed from the tension-producing shock box and could drink in a safe environment. Also, ethanol preference increased following shock experience. These results suggest that drinking ethanol does not bring on tension reduction but, rather, that it is tension that brings on ethanol drinking. Two conditions necessary in order to observe an increased ethanol preference appear to be (1) reduction of fear and (2) sufficient sampling of ethanol to observe its reinforcing effects.

In conclusion, we have shown that there is a relationship between tension and alcohol drinking, but one opposite to that proposed as the tension-reduction hypothesis. Tension reduction induces alcohol drinking, rather than alcohol consumption reducing tension. This can be seen in human drinking behavior. We "unwind" with a drink after a hard day at work, and beer companies often advertise that their particular beer is the one to drink when it is "time to relax" or during weekends. The results of this experiment suggest that organisms do not drink to reduce anxiety but, rather, drink once their anxiety has already been reduced.

\section{REFERENCES}

Anisman, H., \& Waller, T. G. Effects of inescapable shock and shock-produced conflict on self selection of alcohol in rats. Pharmacology, Biochemistry and Behavior, 1974, 2, 27-33.

Cappell, H., \& Herman, P. C. Alcohol and tension reduction: A review. Quarterly Journal of Studies on Alcohol, 1972, 33, 33-64.

CASEY, A. The effects of stress on the consumption of alcohol and reserpine. Quarterly Journal of Studies on Alcohol, 1960, 21, 208-216.

Cicero, T. J., Myers, R. D., \& Black, W. C. Increase in volitional ethanol consumption following interference with a learned avoidance response. Physiology \& Behavior, 1968, 3, 657-660.

Clark, R., \& Polish, E. Avoidance conditioning and alcohol consumption in rhesus monkeys. Science, 1960, 132, 223-224.

Conger, J. J. Alcoholism: Theory, problem and challenge. II. Reinforcement theory and the dynamics of alcoholism. Quarterly Journal of Studies on Alcohol, 1956, 17, 296-305.

DERR, R., \& LINDBLAD, S. Stress-induced consumption of ethanol in rats. Life Sciences, 1980, 27, 2183-2186.

Hoffman, H. S., \& Fleshler, M. A relay sequencing device for scrambling grid shock. Journal of the Experimental Analysis of Behavior, 1962, 5, 329-330.

Masserman, J. H., \& YUM, K. S. An analysis of the influence of alcohol on experimental neurosis in cats. Psychosomatic Medicine, 1946, 8, 36-56.

Mills, K. C., Bean, J. W., \& Hutcheson, J. S. Shock induced ethanol consumption in rats. Pharmacology, Biochemistry and Behavior, 1977, 6, 107-115.

MYERS, R. D., \& Holman, R. B. Failure of stress of electric shock to increase ethanol intake in rats. Quarterly Journal of Studies on Alcohol, 1967, 28, 132-137.

(Manuscript received May 15, 1981; revision accepted for publication December 11, 1981.) 